\title{
El primer institucionalismo económico como movimiento intelectual disidente
}

The first economic institutionalism as a dissident intellectual movement

\author{
Facundo Gustavo Corvalán ${ }^{1}$
}

Gustavo Alberto Masera

\section{Resumen}

El institucionalismo económico es una corriente de pensamiento cuyo nacimiento puede situarse hacia fines del siglo XIX, a partir de la publicación de la obra The Theory of the Leisure Class por parte de Thorstein Veblen y A Sociological View of Sovereignty de John R. Commons, ambas de 1899.

Se demuestra que el institucionalismo fue, en su origen, un movimiento intelectual esencialmente norteamericano con una considerable influencia en los ámbitos académicos y políticos en el período que media entre el fin de la Primera Guerra Mundial y la crisis de la tercera década del siglo XX. Se busca remarcar el aspecto disidente del institucionalismo frente a la dominancia del sistema clásico. Esta labor permite establecer los orígenes y la identidad de un movimiento económico de importancia para el presente de la ciencia económica, puesto que desde hace algunos años se vive un renacimiento institucionalista.

Palabras clave: institucionalismo económico, movimiento disidente, pensamiento económico

\section{Abstract}

Economic institutionalism is a current of thought whose birth can be placed towards the end of the 19th century, from the publication of the book The Theory of the Leisure Class, by Thorstein Veblen and A Sociological View of Sovereignty, by John R. Commons, both of 1899 .

It is demonstrate that institutionalism was, in its origin, an essentially American

\footnotetext{
Recibido: 30 de septiembre de 2019 Aceptado: 14 de diciembre de 2019 Publicado: 20 de diciembre de 2019

${ }^{1}$ Profesor de la Facultad de Ciencias Económicas, Jurídicas y Sociales, Universidad Nacional de San Luis (UNSL) - Investigador del Instituto Multidisciplinario de Estudios Sociales Contemporáneos (IDEHESI CONICET). Correo electrónico: facundogustavocorvalan@gmail.com

${ }^{2}$ Profesor de la Facultad Filosofía y Letras, Universidad Nacional de Cuyo (UNCuyo) - Investigador del Instituto Multidisciplinario de Estudios Sociales Contemporáneos (IDEHESI - CONICET). Correo electrónico: gustavo.masera@gmail.com
} 
intellectual movement with considerable influence in academic and political spheres in the period between the end of First World War and the crisis of the third decade of the twentieth century. It seeks to highlight the dissident aspect of institutionalism against the dominance of the classical system. This work allows to establish the origins and identity of an economic movement of importance for the present of economic science, since for some years ago there has been an institutionalist revival.

Keywords: economic institutionalism, dissident movement, economic thought

\section{Introducción}

En el documento se ponen de relieve algunas características distintivas del primer institucionalismo, llamado también "original", por contraposición a la "nueva economía institucional”. Más allá de la exactitud en la datación temporal de cuándo se genera la transición de una a otra etapa, hay una realidad que se impone, y es la siguiente: que desde su nacimiento y a lo largo del siglo $\mathrm{XX}$, el institucionalismo se ha transformado en un corpus sustancial del pensamiento económico, aunque por momentos en tensión con la teoría convencional. Por tal motivo, se considera necesario reflexionar sobre la cuestión de la disidencia frente al mainstream como caso de estudio de la formación de movimientos económicos nacionales en el período de "profesionalización" de la ciencia económica.

La relevancia del tema se encuentra, entre otros factores, en que las teorías institucionalistas no sólo han enriquecido el panorama de la economía, sino que han facilitado su diálogo con otras ciencias. Pero, además, la propia perspectiva institucionalista se ha difundido hacia otras disciplinas, fenómeno éste que ha sido llamado el "giro institucionalista en las ciencias sociales" (Hodgson, 2009).

Paradójicamente, la contribución de los académicos norteamericanos a su propia historia del pensamiento económico del período en estudio ha sido escasa (Rutherford, 1998). En la literatura económica latinoamericana, un creciente listado de autores (por ejemplo, Ribas Cavalieri, 2009, 2013; Da Silva, 2013; Reis Mourão, 2007; Parada, 2003), ha modificado la tendencia acerca de la desatención que adolecía el tema del primer institucionalismo.

En última instancia, la perspectiva básica del institucionalismo coincide con la noción de "institución" extraída del léxico contemporáneo, ya que a esta se la concibe como un

conjunto de valores, normas y costumbres que definen y regulan en forma duradera -e independientemente de la identidad de las personas individuales-, las relaciones sociales 
y los comportamientos recíprocos de un grupo de sujetos cuya actividad se dirige a conseguir un fin socialmente relevante (Gallino, 1995: 534-535).

El análisis contextual es el más conveniente a los fines de esta investigación. El mismo consiste en ubicar el tiempo, el lugar, y las circunstancias que se encuentran en la génesis y en el devenir de una corriente de ideas. Siguiendo a Echevarría (1999), se proponen los siguientes contextos para el análisis de la actividad científica: educación, aplicación, evaluación, e innovación.

Los contextos permiten evaluar el conjunto de factores presentes en el entorno social, político, eidético-cultural y económico, que actúan como condicionantes en el nacimiento y trayectoria de una corriente de pensamiento, así como de las políticas económicas y legislaciones promovidas desde su ideario específico.

\section{Identidad del Institucionalismo Económico norteamericano: nacimiento y ocaso de un movimiento disidente}

Los tempranos representantes del enfoque institucionalista se concentraron geográficamente en los Estados Unidos de América, y su apogeo como corriente aconteció en el período de entreguerras, durante la belle époque, durante el cual fue la corriente económica dominante. Sobre esta caracterización existe una general coincidencia (Backhouse 2002; Rutherford, 2003; 2011). Lógicamente, las líneas divisoras no son estrictas. Desde otro punto de vista, puede señalarse, aunque el institucionalismo perdió influencia frente al nuevo arsenal teórico e instrumental del keynesianismo, nunca dejó de tener influencia sobre ciertos autores. Hay un perfil de continuidad que nunca se rompe entre la vieja y las nuevas generaciones. Téngase en cuenta, por ejemplo, que los análisis de Simon Kuznets sobre el ingreso nacional comienzan sobre fines de la década de 1930, y que publicará y formará discípulos sin cesar durante más de tres décadas. Y que Gailbraith dará luz a "The Affluent Society" en 1957. Y así... lo que disminuye con el segundo conflicto bélico mundial es el prestigio de la escuela institucionalista.

Se puede fijar el año de 1917 como la fecha de la presentación del institucionalismo en sociedad. Los registros de la American Economic Association (AEA) evocan el encuentro anual como el ámbito en donde se discutió largamente acerca del tema: "The Institutional Approach to Economic Theory". El documento base fue elaborado, en lo fundamental, por Walton H. Hamilton y publicado poco después en uno de los suplementos de la entidad (Hamilton, 1919).

Este evento ha sido ponderado como un hecho simbólico de carácter fundacional en 
la trayectoria del institucionalismo (Hodgson, 2007), fundamentalmente por la declaración explícita de los nombres que defienden su identidad como grupo y por la repercusión que supone discutir el "manifiesto" públicamente. Debe tenerse en cuenta que en la conformación de las instituciones académicas juegan un rol central los aspectos de confianza, reconocimiento y autoridad (Mazzotti, 2008). Es evidente que, con el acto de la AEA, el institucionalismo no sólo define un esquema programático sino que obtiene la legitimación social otorgada por la principal asociación académica de economía del país.

Desde una perspectiva de contexto de educación, es clave la exposición y aceptación por parte de una comunidad disciplinaria específica de los aspectos centrales de la teoría. Además, porque según explica Echevarría (1999), las diversas comunidades científicas compiten por una mayor capacidad explicativa que sus rivales, y además, por conseguir la adhesión de agentes (políticos, tecnólogos, académicos, etc.), que defiendan sus paradigmas en los diversos campos de aplicación.

Tiempo después, la posición del institucionalismo se reafirmará con la convocatoria de la AEA, en 1931, para dedicar una sesión especial al tema: "An Appraisal of Institutional Economics", en el marco crítico de la depresión económica que abatía a los Estados Unidos y al mundo en un futuro incierto. Esta dinámica se vincula, además, con la difusión de las ideas económicas por la estructura social, principalmente en los ámbitos decisorios (Colander and Coats, 1989).

Su decadencia como movimiento influyente en la universidad y en la política se dará en la fase histórica de profundización de la depresión económica, y con el escenario en ciernes del inicio de la Segunda Guerra Mundial. La fecha exacta sólo cumple un rol convencional o didáctico. Puede fijarse el año de 1939, que coincide con el último trabajo publicado en vida por John R. Commons. O tal vez el año 1937, cuando Coase introduce el concepto de "costos de transacción" en su artículo sobre la naturaleza de la firma, y se inaugura con éste una nueva fase en la trayectoria del movimiento institucionalista. No existen dudas acerca de que el conflicto bélico marcará -con la puesta en funcionamiento de la economía de guerra- el ocaso definitivo de esta generación de economistas. Por tal razón, se ha elegido la fecha de 1939 como el cierre de la etapa, aunque lógicamente, el prestigio del movimiento institucionalista sobrevivió en figuras como Wesley Mitchell y Clarence Ayres, quienes actuaron como articuladores generacionales.

Es interesante percibir el vínculo que unió a la AEA con el institucionalismo. Desde la sociología del conocimiento siempre se ha sostenido que la ciencia es una profesión que se desarrolla a través de instituciones. Nada más cierto en este caso. La AEA había nacido en 1885 con el ideal de expandir el pensamiento económico nacional, reemplazando la especulación económica abstracta con un cuerpo de pensamiento 
basado en investigaciones históricas y estadísticas (Haney, 1962:882-883; Coats, 1992; 1993). El institucionalismo intentaría cumplir con tales lineamientos, dándole contenido a esos objetivos.

Lo anterior lleva a considerar la fuerte influencia alemana en los principios que guiaron normativamente a la AEA, y por ende, que incidieron en la formación del institucionalismo. Para Backhouse (1988:271), los objetivos fundacionales de esta organización eran muy semejantes a los de la Verein Fur Sozialpolitik alemana. Es de similar juicio Roll (1939) al sostener que el institucionalismo mantuvo, desde su nacimiento, una fuerte filiación de dependencia con la escuela histórica. El resultado previsible fue el fortalecimiento de las tendencias proteccionistas ya presentes en la mentalidad norteamericana.

Donald Frey (2009) ha llamado la atención acerca del carácter del informe elaborado por Richard Ely para la AEA. El futuro primer secretario de la Asociación, quien había tomado cursos en Heilderberg con Karl Knies, defendía la autonomía y la singularidad del pensamiento económico de los Estados Unidos, lo que en la práctica se traducía en una rebelión contra la teoría clásica.

A primera vista pueden identificarse varios rasgos comunes entre una y otra escuela, la institucionalista y la histórica alemana. Al igual de lo que sucede con otros planteos, la conformidad entre ambas se expresa en una divergencia hacia afuera, contra el pensamiento económico decimonónico de origen británico. Entre otros puntos, se puede destacar la no aceptación de leyes universales válidas para todo tiempo y lugar, así como la reacción frente a la concepción antropológica utilitarista. Asimismo, propugnaban una vía de acceso inductiva e histórica de la economía frente a la deductiva y abstracta de los ricardianos (Dorfman, 1969). De igual forma, tanto una como la otra posee aquello que Seligman (1966) ha denominado el "espíritu de disenso" contra los clásicos. Lo cual, traducido a la política económica, se manifestaba en el abandono de las posturas extremas del laissez-faire. Es por ello que en los fundamentos programáticos se llegó a afirmar que: “(...) the formal defense of laissez faire is gone" (Hamilton, 1919:313).

Sin embargo, existen por lo menos tres contrastes marcados en la experiencia de ambos países. Lo primero a tener en cuenta se refiere a las distintas experiencias históricas en la construcción del Estado-Nación. En segundo término, aparece la brecha acerca de la idea de Estado entre los economistas y juristas pensadores en Alemania con respecto a lo sucedido en el país americano. En el país europeo existe una tradición que viene desde el antiguo cameralismo mercantilista. Finalmente, la visión sobre el devenir temporal de las sociedades, que en el caso de los alemanes evidenciaba una filosofía especulativa de base historicista sobre leyes y morfologías sociohistóricas influenciadas por las concepciones de cuño hegeliano, que no 
interesaba a los americanos.

Es evidente la dificultad de disociar a la formación del institucionalismo económico del flujo de ideas y de procesos sociales en curso en el país del Norte, por lo menos desde su Independencia. Téngase en cuenta que en el contexto de innovación, el elemento significativo es el conjunto de circunstancias políticas, económicas y sociológicas que están relacionadas con el surgimiento o la gestación de una determinada teoría (Echeverría, 1999).

Para algunos analistas, el institucionalismo se articula con el proceso de formación de la "mentalidad económica" en los Estados Unidos (Medema y Samuels, 2004; Rutherford, 1998; Dorfman, 1969). Esta es una interpretación que, en parte, relativiza la influencia de otras teorías y políticas sobre la conformación del pensamiento económico norteamericano. Desde esta perspectiva se plantea la imposibilidad de disociar la formación del institucionalismo económico del flujo de ideas y de procesos sociales en curso en el país americano, por lo menos desde la Guerra Civil. El institucionalismo económico es para ellos un fenómeno distintivo del país del norte. Hay varias razones que fundamentan esta postura. En el caso del surgimiento del enfoque institucionalista, concurren un conjunto de circunstancias asociadas al nacimiento moderno de los Estados Unidos. Es que en términos estructurales, el joven estado representaba un país de características continentales con abundancia de factores económicos. Desde 1830 había aunado a su acervo una frontera en movimiento con amplios desplazamientos migratorios. La incorporación de recursos potencialmente ilimitados se tradujo en planteos muy lejanos al estado estacionario de Ricardo y el pesimismo malthusiano (Engerman and Gallman, 2000). Es que los clásicos insulares estaban dominados por una tensión secular entre población y recursos, que derivaba de manera persistente en fluctuaciones económicas, y, regularmente, en crisis. Estos aspectos se relacionan con lo que Haney (1962:879) ha denominado la influencia de los "factores ambientales" en el pensamiento económico norteamericano.

En la época del meeting fundacional del institucionalismo, Estados Unidos era un país que ingresaba como actor decisivo en la Primera Guerra Mundial, asombrado aún por la ruptura de su proverbial aislamiento, y seguro de haberse incorporado rápidamente -aunque no sin conflictos- a la segunda fase de la revolución industrial. Química, electricidad, motores a combustión, siderurgia, industria pesada, grandes empresas, son testimonios de una nueva topografía económica: cuantiosas inversiones de capital, rápidos cambios tecnológicos, mayores escalas de producción, las cuales muestran un mapa bastante lejano del sistema económico smithiano de libre concurrencia (Rockoff, 2012; Eisnerm, 2011). Son signos, además, de un proceso de agrupamiento de innovaciones -según el sentido otorgado por Mensch (1975)- en el 
inicio de la fase expansiva de los ciclos y como conductoras del crecimiento.

Estos no son datos menores, sino que serán la trama en la que se insertará el esfuerzo de algunos economistas americanos para reflexionar respecto a las condiciones de un capitalismo más complejo en lo socio-económico y de difícil abordaje desde una perspectiva tradicional.

\section{Confluencia con los ideales del american progressivism}

No se podría comprender la cosmovisión americana sin una justa valoración de su profunda veta evangélica, enmarcada en un clima de progresismo moral. El mismo Commons (1934a), en su autobiografía, menciona de entre el conjunto de factores ideológicos que influyeron en su primera formación al Presbiterianismo, al Spencerianismo y al Republicanismo. Es así que en una composición de los elementos intervinientes que se fundirán en el crisol de la mentalidad americana, debería incluirse aquello que Frey (2009) ha denominado como la moral americana, con una fuerte impronta bíblica de origen protestante. Esta dimensión ético-religiosa es visible en los intereses de Commons, quien, a instancias de Richard Ely, organizará hacia fines del siglo XIX el American Institute of Christian Sociology (Dorfman, 1969).

Dos aspectos surgen que deben apreciarse. Debe recordarse que Ely ha sido sumamente criticado desde otras perspectivas económicas (p. e. Rotbhbard, 2002). En lo fundamental, por haber defendido que el Estado es el instrumento elegido por Dios para reformar y cristianizar el orden social. Evidentemente, en Ely se perciben ecos de una postura orgánica de lo social, tan cara a los historicistas alemanes.

Y esto conduce a la relación de las posturas institucionalistas con el socialismo. Es claro que de la visión del mundo de Ely -y también de Commons-, se destaca una voluntad de reforma moral, tan cara a los evangélicos, aunque lejana de posturas socialistas. Como uno de los líderes del progressive movement, Ely exhorta en su obra a una profunda metamorfosis de las instituciones del capitalismo. Deplora tanto la actividad de monopolios y trusts, como abomina de las injusticias que conlleva la evolución de la sociedad industrial. Sin embargo, remarca a cada paso que son los motivos cristianos del social góspel, y no aquellos del evangelio de Marx (o Proudhon), la causa de su predicación en torno a la educación intelectual y moral de los grupos desvalidos, y que fundamentan su prédica en favor de una mejor organización de la clase obrera (Cocks et al., 2009). El claro rechazo al ideario socialista, junto a la intención activa de corregir los desórdenes del progreso, debe comprenderse -en términos comparativos-, como una discordancia con el "socialismo de cátedra” de los profesores alemanes (Roll, 1939). 
En los inicios de la década de 1930 fue evidente que había menguado, para la nueva generación de economistas, la visión religiosa basada en el protestantismo evangélico. Se iniciaba otra etapa en la ciencia social americana, claramente caracterizada por Robert H. Nelson (2001): la era del "neoprogresivismo" secular. El joven Samuelson aparecería, desde sus primeros artículos (p.e. Samuelson, 1938; 1948) como uno de los representantes más notorios de una práctica científica basada ahora en la neutralidad axiológica y en los supuestos reduccionistas de las preferencias reveladas como base de las conductas maximizadoras (Crespo, forthcoming). Evidentemente los economistas científicos de lo que se convertirá en el nuevo canon o "síntesis neoclásica”, mantendrán el objetivo de reformar el estado liberal mediante la ciencia, pero en un contexto ya lejano a la mentalidad de Richard Ely. No puede dejarse de mencionar la influencia decisiva que ejercieron sobre el núcleo filosófico del institucionalismo, John Dewey y el pragmatismo de Charles Peirce y William James (Wilshire, 2000).

En suma, el clima intelectual predominante en el país del Norte, junto a ciertos factores específicos de su desenvolvimiento histórico, hace del institucionalismo económico una corriente de pensamiento original y -en la etapa formativamarcadamente estadounidense. Más aún, algunos historiadores del pensamiento económico (p.e. Ekelund y Hébert; 1999) han llegado a afirmar que el institucionalismo ha sido la única escuela genuinamente americana de economía.

\section{Contribuciones en el primer institucionalismo}

Las figuras emergentes del institucionalismo son Thorstein Veblen, John R. Commons, Wesley Mitchel, John Maurice Clark, Walton Hamilton y Clarence Ayres, junto a una pléyade de figuras secundarias. Algunos autores, Coats por ejemplo, no sólo incluyen en el listado a Richard Ely, sino a algunos otros miembros de la AEA. Schumpeter (1951), con toda su autoridad, considera que Frank W. Taussig, con sus estudios sobre las industrias nacientes y, sobre todo, con la monumental historia de las políticas arancelarias en los Estados Unidos, debería ser ponderado -a pesar de sus diferencias conceptuales- como un antecedente institucionalista.

Del listado sobresale Veblen como el primer autor institucionalista (Samuels, 2004; Seligman, 1965), en función de la originalidad de su planteo y de la creatividad de sus nociones conceptuales ("consumo conspicuo", "instituciones ceremoniales", "era de los ingenieros", "preferencias endógenas”, etc). Gailbraith llegó a valorarlo como el gran teórico social de su época, e iniciador de una nueva tradición. Para otros, su excentricidad representa más un modelo de sociólogo o de antropólogo, quizás, que de un economista. El mismo Schumpeter relativiza su aporte (1951). Sin embargo, 
Veblen escribió como economista, con un objetivo en mente que nunca abandonó, y que le otorga coherencia interna a su obra: generar una crítica de los fundamentos neoclásicos, y del capitalismo mismo, junto a la proposición -en su estilo- de una teoría del desarrollo económico y social con instituciones en permanente cambio (Ekelund y Hébert, 1999).

La atracción duradera de este autor se sitúa en su fundamentación evolucionista de las instituciones. Cuando elabora un análisis sobre la clase ociosa, alega que las instituciones no son sólo el resultado de un proceso de adaptación que transformaba los tipos anteriores dominantes de aptitudes y actitudes, sino que eran métodos especiales de relaciones sociales y humanas, y, además, factores eficientes de selección (Veblen, 1899; 1914; 1919). En años recientes se ha valorado el reconocimiento temprano del evolucionismo -en su versión darwiniana- por parte de Veblen (Hodgson, 2002). Veblen murió en 1929, el año del crack financiero de Wall Street. No se conoce, por lo tanto, qué hubiera afirmado sobre la crisis. Pero, algo paradójico en un intelectual evolucionista, subestimó la fortaleza del capitalismo para adaptarse a las nuevas condiciones del entorno.

$\mathrm{Si}$ Veblen fue el teórico sagaz e innovador algo incomprendido, John Rogers Commons representó para muchos otros el verdadero precursor, un auténtico representante de la identidad cultural norteamericana. Diversos estudios han puesto de manifiesto las divergencias que separaban a Commons de Veblen, por ejemplo sobre el lugar del individuo en el proceso social (Broda, 1998). En actitud y personalidad, son autores que presentan muchas diferencias entre sí, pero de igual modo presentan varios elementos en común.

Oliver Williamson (1975) ha valorado a Commons como el iniciador del análisis de los costos de transacción. Otro de sus aportes es el concepto de "acción colectiva", que desarrolla en diversos artículos, y que termina de dar forma en su último libro, editado póstumamente (Commons, 1950). Lo central de su contribución radica en la vinculación del análisis económico con la evolución de las instituciones específicas que se generan en un ámbito político- administrativo, nacional o estadual. Los mecanismos de regulación de los sectores económicos, especialmente en lo que respecta a la legislación del trabajo, con una fuerte orientación a la reforma social, son algunas de las cuestiones sustanciales que interesarán de aquí en más al institucionalismo (Rutherford and Samuels, 1996).

La concepción económica de Commons se conjuga con un "idealismo práctico" que busca la mejora de las condiciones de vida y de organización del movimiento obrero, aunque con el objetivo final de lograr finalmente un mejor funcionamiento de la economía en el conjunto social. A diferencia de la tradición clásica, entiende la competencia como un proceso socialmente construido y regulado por las normas 
institucionales (Ramstad, 2000), las cuales pueden cambiar de una época a otra y de una sociedad a otra. Las instituciones están, en este sentido, históricamente condicionadas, y, a su vez, son parte de la estructura que estipula y restringe los comportamientos sociales. En efecto, la profunda moralidad de Commons y su aspiración ética es visible en su descripción de la situación de la clase obrera, agrícola e industrial. Sus observaciones sobre la causa de la pobreza en la vida de los inmigrantes, o sobre el origen de las Trade Unions, no sólo son reflexiones históricas, sino que se desprende de ellas una meta reformista.

\section{Programas de investigación y principales núcleos teóricos del primer institucionalismo}

Puede notarse que no todo el institucionalismo es idéntico en sus planteos ni representa un cuerpo unificado de pensamiento. Por el contrario, hay bastante heterogeneidad en sus planteos. Podrían señalarse diferencias según la procedencia de los autores, y así hablar de diversos institucionalismos: el de Texas, el de Illinois, etc. Más allá de las diferencias locales, Rutherford (1994) afirma que hay dos grandes programas de investigación en el primer institucionalismo, con fuertes puntos de conflicto ideológico -en el sentido de polémica de ideas en torno a la organización social- entre ellos.

La primera línea estaría asociada al corpus teórico de Veblen-Ayres, elaborado sobre la dicotomía entre la esfera de los negocios y la dimensión industrial de la economía. $\mathrm{Su}$ foco se encuentra en el establecimiento de las convenciones sociales y los efectos de las nuevas tecnologías sobre las instituciones. Además, si por un lado se plantean reparos contra la psicología del hombre económico de los clásicos, basada en la búsqueda del interés personal y en la ética utilitarista, por otro lado se aducen consideraciones orientadas al hábito como motivo dominante. Para Veblen (1914), lo central de la nueva sociedad se ubica en el ingreso a la era de la máquina industrial. Shigeto Tsuru (1993) sostendrá que Veblen y Marx coinciden en identificar a la tecnología como el factor decisivo del crecimiento económico. Agregaba el economista japonés que, para estos pensadores, el progreso (o desenvolvimiento de las fuerzas productivas) era un proceso objetivo, acumulativo e independiente de los deseos o acciones de los hombres de negocios.

Clarence Ayres representa un nexo con la generación posterior, al reflexionar sobre el cambio tecnológico y la dinámica del sistema industrial. Con su obra (Ayres, 1952; 1962) contribuyó a fundamentar filosóficamente el enfoque institucionalista a partir de su filiación con la tradición pragmatista- instrumentalista de Dewey (Seligman, 1965). En otro orden, realizó un valioso aporte para superar la insularidad 
norteamericana, tal como ha reconocido Coats (1992), mediante el establecimiento de vínculos con economistas británicos de intensas aspiraciones reformistas, como Hobson y Tawney. Esta relación no es de extrañar, si se tiene en cuenta el temprano interés de Ayres por la perspectiva ética de la economía, tal como lo demuestra el tema elegido para su disertación doctoral (Ayres, 1918).

La segunda vía se fundamenta en los trabajos de Commons y de Walton Hamilton. La misma se centra en los estudios sobre la ley, los derechos de propiedad, la economía de las transacciones, la distribución de los ingresos y la evolución de las organizaciones. Uno de los puntos clave es la cuestión de la resolución de conflictos entre grupos de presión (Hodgson, 2003). Commons desarrolló teorías sobre el cambio institucional, tratando de comprender la estructura industrial de su tiempo. Si bien en una primera época se concentró en el estudio de los sindicatos y el movimiento obrero, con el tiempo su investigación devino en un examen más completo de las bases del capitalismo como sistema (Commons, 1924; 1931). Esta vía de reflexión ha seguido influenciando a muchos analistas de la economía moderna, sobre todo en los aspectos que vinculan a la economía con la legislación, las decisiones judiciales, y el Gobierno. Según Knight (1952), la rama del institucionalismo que personifica Commons, sobre todo en su última etapa (Commons, 1934; 1950), se fundamenta en la idea del control colectivo de la conducta individual mediante la acción de las reglas operantes en la sociedad: a) que actúan en la formación de las instituciones; b) que emanan como elaboración de las cortes; c) como leyes del Congreso, y; d) las decisiones de la Corte Suprema.

Podría agregarse un tercer programa de investigación, con los análisis de Wesley Mitchell (1913). Esta rama extendió el conocimiento de grandes series históricoestadísticas, a partir de la acción de equipos de trabajo técnicamente especializados y reunidos en torno al National Bureau of Economic Research (NBER). Los estudios que Mitchell lideró, otorgaron al enfoque institucionalista de una metodología útil para analizar la base empírica de los ciclos económicos y de negocios, y al mismo tiempo lo introdujo en los rudimentos del análisis macroeconómico (Mitchell, 1913; Burns and Mitchell, 1946). Mitchell desarrolló, específicamente, la teoría del "ciclo autogenerador". La misma le permite explicar el proceso continuo de prosperidad depresión - prosperidad, donde cada fase del ciclo hereda un cúmulo de circunstancias de las fases pasadas, que condicionan la formulación de las pautas de comportamiento de las fases futuras. Mitchell realiza un análisis de las instituciones de una economía monetaria desarrollada, que tiene en su seno el impulso hacia el ingreso y la ganancia, a modo de fuerzas contribuyentes, a las fluctuaciones económicas (Lee, 1965). Esta línea de trabajo conecta a los institucionalistas con la obra de Simon Kuznets, premio Nobel en 1971. Kuznets fue un discípulo eminente 
de Mitchell, y su obra basada en el análisis de las cuentas nacionales y de las series empíricas sobre el crecimiento económico, no podría ser entendida sin referencia a su predecesor. Por ser básicamente empirista, esta es una de las ramas del institucionalismo perfilada como más "moderna” y "científica”.

El contexto de evaluación permite revisar la sucesión de las teorías en el marco de un programa de investigación. En un examen diacrónico de los sistemas de pensamiento se discuten los aspectos de renovación de este, o la adecuación de algunas de sus hipótesis a nuevos problemas (Echevarría, 1999). Una labor imprescindible sería, entonces, comprender el desenvolvimiento del enfoque institucionalista en sus distintas fases históricas. Pero, puesto que este propósito escapa a este documento, sólo se harán breves consideraciones en torno a la unidad del movimiento, poniendo de relevancia más sus aspectos de continuidad que de cambio.

Describir la trayectoria de los institucionalistas americanos implica el reconocimiento de un refinamiento progresivo de las teorías, a causa de las polémicas internas y externas; también supone la existencia de una invariante por entre los numerosos autores y caminos de investigación. Con respecto a este "núcleo teórico permanente" del institucionalismo económico, ha afirmado Douglass North (1989: 12) que la idea central que se mantiene a lo largo de todas las generaciones de pensadores es que las “instituciones políticas y económicas existen -y que importan”. Coase (1984:231) abundará con la idea de que la economía institucional moderna comprende la actuación del hombre inmerso en el marco que imponen, a modo de restricciones, las instituciones concretas de la vida social.

La visión central del institucionalismo económico se caracteriza, según Pirou (1939), por la importancia otorgada al rol que juegan las instituciones en la actividad económica, de manera que esta última es más un proceso social organizado, que un juego de cálculo individual.

El núcleo permanente se relaciona, además, con los elementos en común que existen entre los programas de investigación del primer institucionalismo. Según la síntesis elaborada por Haney (1962) estos serían los siguientes: 1) Las conductas y las reglas de los grupos, y no los precios, son los temas que se encuentran en el núcleo de la estructura económica; 2) El comportamiento humano no es algo estático, sino cambiante, por lo tanto, las generalizaciones económicas deberían ser adecuadas a un tiempo y lugar específico; 3) Debe enfatizarse el análisis de las costumbres, de los hábitos y de las leyes, como modos de organización de la vida económica; 4) Hay importantes motivos y factores que influencian a los individuos que no pueden estar sujetos a medición, y; 5) Los desajustes en la economía deben ser considerados como situaciones normales, y su reiteración -más que una pérdida de rumbo de un equilibrio general- revelan la necesidad de mejora en las instituciones del capitalismo. 
Otro tópico común a los institucionalistas se refiere a que estos fueron pioneros en advertir la importancia del cambio tecnológico y de los procesos de industrialización en el sistema económico (Medema and Samuels, 2004). Estos autores sostienen, asimismo, que el enfoque institucionalista comporta una teoría del cambio social y una teoría del control social. Mientras que la primera incluye una orientación activista hacia las instituciones sociales; la segunda pone de relevancia la acción colectiva que se manifiesta en los procesos económicos, condicionada por las regulaciones económicas y legales. Téngase en cuenta que Hamilton (1919), en una clara referencia a Veblen, manifestaba la necesidad de una legislación orientada al control social de los negocios.

Los institucionalistas, además, desarrollaron una teoría del valor, ya no basada en los intercambios, sino situada en el entramado de reglas jurídicas, hábitos y normas morales, todo lo cual dirige en general a la actividad económica misma y, en particular, orienta el comportamiento en los mercados, los cuales funcionan dentro de las estructuras institucionales y organizacionales del sistema económico.

Un aspecto importante radica en que ninguno de los institucionalistas se concebía a sí mismo como un mero observador de la sociedad de su tiempo. Para ellos la economía no era una ciencia neutral, susceptible de ser practicada sin pensar en sus efectos políticos y sociales. Más bien, manifestaban que la actividad económica se desarrollaba sin cesar en un entramado de reglas jurídicas, hábitos, normas y comportamientos, que eran pasibles de ser reformados.

En etapas posteriores surgieron autores como Nelson y Winter (1982), quienes incorporaron argumentos evolucionistas, desde una base teórica neoschumpeteriana, a los propios de la tradición institucionalista. Desde esa fecha se generó un rápido crecimiento de las publicaciones específicas del programa de investigación evolucionista. Las contribuciones muestran, desde esa fecha, una gran expansión geográfica de este programa, con grupos de investigación diseminados por fuera de los Estados Unidos de América. Estos últimos combinan elementos institucionalistas sobre los cambios acumulativos y las modificaciones estructurales en la organización económica, desde una perspectiva crítica del crecimiento neoclásico. Algunos de los tópicos que aparecen son los siguientes: ciclos y sucesión de los paradigmas tecnoeconómicos (SPRU, Universidad de Sussex); dinámica industrial y cambios corporativos (grupo Druid; grupo CIRCLE, Dosi, Malerba, etc.); innovación \& path dependency (Jan Fagerberg); aproximación a enfoques regulacionistas (Coriat, etc.).

\section{El primer institucionalismo como disidencia y grupo de influencia}


Los autores institucionalistas consideraron explícitamente que su enfoque se diferenciaba en cuestiones sustanciales con el paradigma normal de la ciencia económica. Según Hodgson (2014), de entre todos los miembros del movimiento institucionalista, el más potente crítico de la economía neoclásica fue Veblen, a partir de su negativa a aplicar las nociones de maximización de la utilidad y de equilibrio. Pero, más allá de si la resistencia fue total o solamente hacia algunas categorías, la relación con la corriente principal conduce a la discusión sobre el significado verdadero de disidencia.

Para resolver esta dificultad, Medema (2008) ha identificado diversas formas de concebir el disenso de una corriente. Una primera acepción, muy amplia, sugiere cualquier cuestionamiento -relativamente serio y con fundamentos científicos- sobre algún aspecto del standard. Una segunda línea, más acotada que la anterior, se relaciona con alguien que plantea controversias en alguna área específica de la teoría convencional, ya sea el comercio o los temas monetario-financieros. Una tercera noción se refiere especialmente al debate sobre los fundamentos de un sistema, o acerca de los principios que rigen su análisis económico. Una cuarta implica el examen, e incluso el abierto rechazo, de la mayor parte de los principales elementos teóricos del paradigma normal. En muchos casos esta postura admite la presentación de un esquema teórico alternativo construido en torno a una nueva "escuela económica”. El mismo Medema pone como ejemplos de última categoría a los institucionalistas, mencionando explícitamente a Thorstein Veblen y a Clarence Ayres. Una concepción similar sobre lo que significa discrepar con la corriente principal es la que ha llevado a Arestis y Sawyer (2000) a incluir en su obra a los máximos representantes del institucionalismo original, esto es, a Veblen, Commons, Mitchell y Ayres, dentro del grupo de "economistas disidentes".

Por su parte, Joseph Dorfman (1969), en su historia de la contribución norteamericana al pensamiento económico, incluye en la tercera parte del segundo volumen un capítulo que llama "La voz de la disidencia", en el cual desarrolla principalmente la obra de Commons. Esta tesis sobre la disidencia de los institucionalistas ha sido refrendada por Warren Samuels (1998) en una dedicatoria: "In tribute to John R.Commons and Thorstein B.Veblen, for their contributions to the demystification of economy, polity and society".

Puede concluirse señalando que en las obras mencionadas existe una coincidencia unánime sobre el valor crítico y reformista del enfoque institucionalista. De un lado, se reconoce la capacidad de examinar sin reservas la tradición liberal, incluso en lo que se refiere al rol del Estado. De otro, se pondera la fundamentación de una praxis socio-política orientada a la resolución del conflicto entre capital y trabajo. Según palabras de Dorfman (1969), quien se había formado intelectualmente como 
discípulo de Wesley Mitchell, los institucionalistas fueron pensadores que consagraron una parte sustancial de su interés científico a las consecuencias sociales del pensamiento económico y, recíprocamente, el examen del orden social los condujo a concebir sobre nuevas bases sus conceptos económicos.

A pesar de lo expuesto, debe observarse que existen diferencias en la ponderación del carácter rupturista del institucionalismo. Por ejemplo, si bien la confrontación de los institucionalistas económicos se extiende también frente a gran parte de los neoclásicos y marginalistas, trabajos como el realizado por Vanberg (1989), para demostrar que el concepto de "institución” en Carl Menger y en John Commons -en apariencia irreconciliables- es compatible y complementario, hacen pensar que algunas generalizaciones tienden a ser injustas y no captan la riqueza de matices que poseen autores tan complejos. La interpretación de Hodgson (2009), por el contrario, señala que Menger concibe un irreal "estado de naturaleza" libre de instituciones (por ejemplo, en su estudio sobre el origen del dinero), algo que resulta inaceptable para el economista británico.

Un factor clave para la identidad del institucionalismo como corriente es la participación gubernamental y qué, específicamente, implica el desarrollo de roles oficiales para los economistas; fenómeno que se relaciona, también, con la creciente profesionalización de la ciencia económica en el mundo anglosajón (Backhouse, 2002; Coats, 1993).

En el ámbito norteamericano, este proceso se dio en distintos planos. De un lado, mediante la colaboración en los distintos comités y departamentos oficiales que se formaron para el esfuerzo de guerra con la movilización de la economía, así como en la coordinación industrial y el control de precios. De otro, en el período de paz, los institucionalistas promovieron nuevas legislaciones laborales (p.e. "The National Industrial Recovery Act”), acuerdos antimonopolios y regulaciones de empleo (Bach, 1954). El ejemplo más acabado de esta colaboración con el gobierno fue la puesta en marcha del National Bureau of Economic Research por parte de Mitchell, después de acabada la Primera Guerra Mundial.

Un caso ejemplar se dio a partir de la incorporación de varios intelectuales de raigambre institucionalista a la administración de Franklin D. Roosevelt, presidente de los Estados Unidos desde 1933 (Engerman and Gallman, 2000). Otro caso para citar se refiere al poderoso grupo asociado al Gobernador de Wisconsin, Robert de La Follette (Rothbard, 2002). También es de tener en cuenta la participación en las diversas comisiones en el período de entreguerras.

Es un hecho incuestionable -e inédito en la historia económica- que un programa de política económica como el "Nuevo Trato" ("New Deal"), en su formulación e implementación, fuera profundamente influenciado por un grupo de economistas y 
académicos, en este caso los institucionalistas americanos. En la literatura especializada se ha denominado a este proceso de incorporación de asesores, o de funcionarios que participan del proceso de toma de decisiones, como la formación de “comunidades epistémicas" (Evans and Newnham, 1998), lo cual va más lejos que el concepto de think-tanks. Este procedimiento, muy frecuente por otra parte en el mundo contemporáneo, y no sólo en el ámbito de la economía, implica que redes de especialistas con una determinada formación científica, e incluso ideológica, se insertan en ámbitos estratégicos de la estructura del Estado, y desde allí inciden en la formulación de las políticas. En síntesis, la intervención de los institucionalistas en asuntos gubernamentales implicó el directo involucramiento en los programas de gobierno. En efecto, los integrantes del movimiento se vieron en la obligación moral -basada en su concepción del control social, del pragmatismo y del instrumentalismode participar activamente en el proceso de reforma económica y social. Es que los defensores del enfoque institucionalista no sólo mantenían una visión compartida relativa al significado y a los objetivos de la ciencia, sino que, fundamentalmente, estaban de acuerdo en el deseo de utilizarla como instrumento de intervención social (Rutherford, 2011).

Lo expuesto coincide con el contexto de aplicación de una teoría científica, dado que en el mismo se examina el ámbito específico de la realidad en que es empleada una teoría, en relación a la búsqueda de beneficios concretos para una comunidad dada (Echevarría, 1999). Puede observarse que la contribución de los institucionalistas a la vida gubernamental es un caso que muestra ribetes de una aparente contradicción: un grupo de economistas disidentes trabaja en las esferas de gobierno. Sin embargo, esta supuesta discordancia se comprende mejor si se tienen en cuenta los factores que participan en el surgimiento de la mentalidad americana, y específicamente si se aprecia en toda su dimensión la concepción filosófica que se encuentra en los fundamentos del primer institucionalismo.

De manera convergente, en la acción pública desplegada por los institucionalistas se ha querido desmerecer su labor bajo el reproche de antiteóricos. En efecto, se ha reprochado la ausencia de un cuerpo teórico acabado en el primer institucionalismo, e incluso se ha generado debate sobre si los institucionalistas originales tuvieron o no una agenda de investigación positiva (Soule, 1961), aunque esta afirmación aparece como exagerada. Es verdad que si se compara la obra de cualquiera de los institucionalistas tempranos con la de Alfred Marshall, o la de Carl Menger, por ejemplo, la supremacía de la arquitectura teórica debida a estos últimos por sobre los primeros queda a la vista. No obstante, Rutherford (1994; 1998) en primer lugar, y posteriormente Hodgson (2009), han negado enfáticamente la acusación de antiteóricos dirigida a los institucionalistas. También se observa -y aquellos que han 
frecuentado la historia del pensamiento económico estarán de acuerdo-, que esta crítica se repite contra toda postura de cuño historicista, y que la misma viene de lejos, especialmente de la querella de los métodos. A fin de acallar las voces negativas, habría que recordar que el mismo Hamilton afirma en su manifiesto que la economía institucional es, substancialmente, teoría económica, y que por eso mismo tiene la capacidad de unificar todos los esfuerzos particulares de investigación de la ciencia económica (Hamilton, 1919:309 y 312).

\section{Reflexiones finales}

Desde una perspectiva de contextos históricos, se ha buscado una integración de los aspectos externos e internos de un sistema de ideas. Esta labor permitió identificar los factores ambientales de la corriente, y las influencias recibidas en su origen. Se ha reconocido que la ascendencia procedente de la Escuela Histórica Alemana fue significativa. Pero si el influjo de los historicistas continentales fue importante, no deben olvidarse las fuerzas intelectuales de reacción frente a la escuela clásica y sus intentos de diferenciación frente a la corriente neoclásica.

El institucionalismo se constituyó en un movimiento con identidad propia, y estrechamente vinculado a los debates científicos e ideológicos generados en el ámbito de la American Economic Association. Según los propios representantes del enfoque institucionalista, éste respondía más adecuadamente que otros sistemas de ideas, a las necesidades concretas de organización y regulación que suscitaba el desarrollo industrial, así como las exigencias de reforma social que imponía el crecimiento económico de los Estados Unidos en las primeras décadas del siglo XX.

En relación con la corriente principal de la economía, la afirmación de la propia identidad del institucionalismo fue claro desde el inicio. Por estas razones, se ha evaluado que el primer institucionalismo económico fue un movimiento de disidencia frente a la corriente principal. Sus representantes no sólo desafiaron al mainstream en aspectos teóricos y metodológicos centrales, sino que elaboraron un consenso inédito sobre la centralidad de las instituciones, considerándolas el principal factor explicativo del comportamiento de una economía, lo cual marca la vigencia y la actualidad del primer institucionalismo.

En suma, el institucionalismo original representó una renovación en el campo de la ciencia económica, siendo ésta la concepción de que el hombre no sólo está confinado en los marcos institucionales, sino que su ser social está "ontológicamente" -al decir de Hodgson- constituido por instituciones. Y esta afirmación se encuentra en el núcleo de los desarrollos neoinstitucionalistas. 


\section{Bibliografía}

AYRES, C. (1918) The Nature of the Relationship between Ethics and Economics, Chicago: Illinois, University of Chicago Press, Philosophic Studies n. 8.

AYRES, C. (1952) The Industrial Economy, Boston: Houghton Mifflin.

AYRES, C. (1962) The Theory of Economic Progress, New York: Schocken.

BACKHOUSE, R. (1988) Historia del Análisis Económico Moderno, Madrid, Alianza Universidad.

BACKHOUSE, R. (2002) The Penguin History of Economics, London, Penguin books.

BURNS, A.; MITCHELL, W. (1946) Measuring Business Cycles, Washington D.C., National Bureau Of Economic Research, Studies in Business Cycles No.2.

COASE, R. (1984) “The New Institutional Economics: A Symposium”, In: Zeitschrift für die gesamte Staatswissenschaft / Journal of Institutional and Theoretical Economics, Bd. 140, H. 1, (März 1984), pp. 229-231.

COATS, A.W. (1992) On The History Of Economic Thought, British and American Economic Essays, London, Routledge, vol. 1.

COATS, A. W. (1993) The Sociology and Professionalization of Economics, British and American Economic Essays, London, Routledge, vol. 2.

COLANDER, D.; COATS, A.W. (1989) The spread of economic ideas, Cambridge: UK, Cambridge University Press.

COMMONS, J.R. [1924] (1968) The Legal Foundations of Capitalism, Madison: University of Wisconsin Press.

COMMONS, J.R. (1931) "Institutional Economics”, American Economic Review, vol. 21 (Dec), pp. 648-657.

COMMONS, J.R. (1934) Institutional Economics, New York: Macmillan.

COMMONS, J.R. (1934a) Myself, Madison: University of Wisconsin Press.

COMMONS, J.R. (1950) The Economics of Collective Action, New York: Macmillan.

DA SILVA, V.L. (2013), "Da matriz historicista ao holismo metodológico no institucionalismo vebleniano”, Economia e Sociedade, Campinas, V.22, N.2 (48), p. 335-366, ago.

DORFMAN, J. [1948] (1969) The Economic Mind in American Civilization, New York: Augustus M. Kelley Publications. Hay traducción española, J. Dorfman. El 
Pensamiento Económico en la Civilización Norteamericana, México D.F., Guarania, tres tomos, 1957.

EISNER, M.A. (2011) The American Political Economy. Institutional Evolution of Market and State, London and New York, Routgledge.

ECHEVERRIA, J. (1999) Introducción a la Metodología de la Ciencia, Madrid, Cátedra, 1999

EKELUND, R.; HÉBERT, R. (1999). Historia de la Teoría Económica y de su Método, Madrid, Mc Graw Hill.

EVANS, G.; NEWNHAM, J. (1998) The Penguin Dictionary of International Relations, London, Penguin Books.

FREY, D.E. (2009) America's Economic Moralists. A History of Rival Ethics and Economics, New York, State University of New York Press.

GALLINO, L. (1995) Diccionario de Sociología, México D.F., Siglo XXI editores.

HAMILTON, W.H. (1919) “The Institutional Approach to Economic Theory”, The American Economic Review, Vol.9, No.1, Supplement, Papers and Proceedings of the Thirty-First Annual Meeting of the American Economic Association (Mar.), pp. 309-318.

HODGSON, G. (2002) “Darwinism in economics: from analogy to ontology”, Journal of Evolutionary Economics, 12:259-281.

HODGSON, G. (2003) "John R. Commons and the Foundations of Institutional Economics”, Journal of Economic Issues, Vol.XXXVII, No.3. September, pp. 547576.

HODGSON, G. (2004) The Evolution of Institutional Economics: Agency, Structure and Darwinism in American Institutionalism, London and New York, NY: Routledge.

HODGSON, G. (2007) Economía Institucional y Evolutiva Contemporánea, México, Universidad Autónoma Metropolitana.

HODGSON, G. (2009) "Institutional Economics into the Twenty-First Century", Studi I Note di Economia, XIV, N.1, pp. 03-26.

HODGSON, G. (2014) “On Fuzzy Frontiers and Fragmented Foundations: Some Reflections on the Original and New Institutional Economics", Journal of Institutional Economics, 10 (4), December.

LEE, M.W. (1965). Fluctuaciones Económicas. Crecimiento y Estabilidad, Buenos Aires, Eudeba. 
MAZZOTTI, M. (Ed.) (2008) Knowledge as Social Order: Rethinking the Sociology of Barry Barnes, Aldershot, UK: Ashgate Publishing.

MENARD, C.; SHIRLEY, M. (editors) (2005) Handbook of New Institutional Economics, Berlin: Springer.

MITCHELL, W. (1913) Business Cycles, Berkeley: University of California Press.

NELSON, R.H. (2001) Economics as Religion. From Samuelson to Chicago and Beyond, Pennsylvania, USA, The Pennsylvania State University Press.

NELSON, R.; WINTER, S. (1982) An Evolutionary Theory of Economic Change, Cambridge: Mass., The Belknap Press of Harvard University Press.

NORTH, D.C.; THOMAS, R.P. (1989) “Una Teoría Económica del Crecimiento del Mundo Occidental”, Revista Libertas VI: 10 (Mayo), Eseade.

NORTH, D.C. (1994), "Economic Performance Through Time”, Nobel prize lecture (December 19, 1993). Publicado también en: The American Economic Review, 84 (3):359-368.

OLSON, M. (1965) The Logic of Collective Action: Public Goods and the Theory of Groups, Cambridge, MA: Harvard University Press,

RADER, B.G. (1966) The Academic Mind and Reform: The Influence of Richard T. Ely in American Life, Lexington: University Press of Kentucky.

REIS MOURÃO, P. (2007) "El Institucionalismo norteamericano: orígenes y presente", Revista de Economía Institucional, Vol.9, Nro.16, primer semestre, pp. 315-325.

RIBAS CAVALIERI, M.A. (2009) O Surgimento do Institucionalismo NorteAmericano: Um Ensaio Sobre o Pensamento e o Tempo de Thorstein Veblen, Belo Horizonte, MG UFMG/Cedeplar, Tese Doutorado em Economía. RIBAS CAVALIERI, M.A. (2013) "O surgimento do institucionalismo norteamericano de Thorstein Veblen: economia política, tempo e lugar", Economia e Sociedade, Campinas, V.22, N.1 (47), p. 43-76, abr.

ROBERTSON, R.M. (1967) Historia de la Economía Norteamericana, Buenos Aires, Editorial Bibliográfica Omeba 2a, Edición.

ROCKOFF, H. (2012). America's Economic Way of War, Cambridge: Cambridge University Press.

ROLL, E. (1939) History of Economíc Thought, London, Faber and Faber.

ROTHBARD, M. (2002) “Richard T. Ely. Paladin of the Welfare-Warfare State”, The Independent Review, V.VI, N.4, Spring 2002, pp. 585-589. 
RUTHERFORD, M. (1994) Institutions in Economics. The Old and the New Institutionalism, Cambridge University Press.

RUTHERFORD, M. (Ed.) (1998) The Economic Mind in America: Essays In The History Of American Economics, London and New York, Routledge.

RUTHERFORD, M. (2001), "Institutional Economics: Then and Now", Journal of Economic Perspectives, Volume 15, Number 3, Summer, pp. 173-194.

RUTHERFORD, M. (2003) "American Institutional Economics in the Interwar Period”, in W. SAMUELS, J. BIDDLE and J.B. DAVIS, op. cit., pp. 360-376.

RUTHERFORD, M. (2011) The Institutionalist Movement in American economics, 1918- 1947: science and social control, Cambridge (UK): Cambridge University Press.

RUTHERFORD, M.; Samuels, W. (editors) (1996) John R. Commons: Selected Essays, London, Routledge.

SAMUELS, W. (2004) “Thorstein Veblen as economic theorist”, W. Samuels et. al (edit.), Essays on the History of Economics, London and New York, Routgledge, pp. 271-305.

SAMUELSON, P. (1938) “A note on the pure Theory of Consumire's Behaviour”, Economica, 5/17, pp. 61-71.

SAMUELSON, P. (1948) "Consumption Theory in Terms of Revealed Preference", Economica, 15/60, pp. 243-253.

SCHUMPETER, J. (1951) Ten Great Economists from Marx to Keynes, New York: Oxford University Press.

SELIGMAN, B. (1965) Principales Corrientes de la Ciencia Económica Moderna, Barcelona, Oikos-Tau.

TSURU, S. (1993) Institutional Economics Revisited, Cambridge, Cambridge University Press, Raffaele Mattioli Foundation.

VEBLEN, T. [1899] (1994) The Theory of the Leisure Class. An Economic Study in the Evolution of Institutions, New York, Dover Thrift Editions.

VEBLEN, T. (1914) The instinct of workmanship, and the state of the industrial arts, New York: Augustus Kelley.

VEBLEN, T. (1919) "Why is economics not an evolutionary science?", In: The place of science in modem civilization and other essays, New York: B.W. Huebsch, p. 5681. 